\title{
Getting By With a Little Help From Self and Others: Self-Esteem and Social Support as Resources During Early Adolescence
}

\author{
David L. DuBois, Carol Burk-Braxton, Lance P. Swenson, Heather D. Tevendale, \\ Erika M. Lockerd, and Benjamin L. Moran \\ University of Missouri-Columbia
}

\begin{abstract}
Influences of social support and self-esteem on adjustment in early adolescence were investigated in a 2-year longitudinal study $(N=350)$. Multi-informant data (youth and parent) were used to assess both overall levels and balance in peer- versus adult-oriented sources for social support and self-esteem. Findings obtained using latent growth-curve modeling were consistent with self-esteem mediating effects of social support on both emotional and behavioral adjustment. Lack of balance in social support and self-esteem in the direction of stronger support and esteem from peer-oriented sources predicted greater levels and rates of growth in behavioral problems. Results indicate a need for process-oriented models of social support and self-esteem and sensitivity to patterning of sources for each resource relative to adaptive demands of early adolescence.
\end{abstract}

Positive feelings of self-worth (self-esteem) and supportive relationships with others (social support) each have been conceptualized as resources that promote successful adaptation during adolescence (Compas, Hinden, \& Gerhardt, 1995; Petersen, Kennedy, \& Sullivan, 1991; Sandler \& Twohey, 1998). The challenging array of biological, cognitive, and social changes that characterize early adolescence in particular may introduce changes in levels and configuration of these resources that have significant implications for coping processes (Lerner et al., 1996). Favorable views of the self, as an internal asset, appear to be valuable in helping young adolescents to avoid emotional difficulties (e.g., depression; Harter, 1999) as well as in reducing the likelihood of their engaging in maladaptive behaviors (e.g., delinquency) as a response to negative feelings of self-regard (Kaplan, 1996). Similar benefits are apparent for the wide-ranging types of external support that youth may receive at this age, from tangible assistance with practical concerns such as schoolwork to simply the opportunity to have others listen to and validate feelings (Berndt \& Hestenes, 1996; Cauce, Mason, Gonzales, Hiraga, \& Liu, 1996; Sandler, Miller, Short, \& Wolchik, 1989).

Most research, however, has not investigated implications of social support and self-esteem for the adjustment of young adolescents within an integrative, developmentally oriented framework. The conceptual framework used to guide the present research highlights several issues for consideration in this regard (see Figure 1). These include (a) the implications that not only

David L. DuBois, Carol Burk-Braxton, Lance P. Swenson, Heather D. Tevendale, Erika M. Lockerd, and Benjamin L. Moran, Department of Psychological Sciences, University of Missouri-Columbia.

This research was supported by National Institute of Mental Health Grant DHHS 5 R29 MH55050 to David L. DuBois. We thank the students, staff, and parents of the Columbia Public Schools, Columbia, Missouri, for their participation in and support of the research.

Correspondence concerning this article should be addressed to David L. DuBois, 210 McAlester Hall, Department of Psychological Sciences, University of Missouri-Columbia, Columbia, Missouri 65211. E-mail: DuBoisD@missouri.edu overall levels but also developmental patterning or balance in sources of social support and self-esteem may have for the adjustment of young adolescents, (b) developmental changes that may allow self-esteem to assume an important role in mediating the effects of social support in early adolescence, and (c) age-related shifts or changes that may occur in relations of social support and self-esteem with adjustment as youth progress through this transitional period.

\section{Developmental Patterning in Sources of Social Support and Self-Esteem During Early Adolescence}

Extensive prior theory and research have addressed the role of overall availability of social support and self-esteem in facilitating adjustment during adolescence (Compas et al., 1995; Steinberg \& Morris, 2000). Newly emerging properties of social relationships (e.g., self-disclosure) and the self-system (e.g., capacity for selfreflection) during early adolescence (Hamburg, 1974), moreover, point to the significance of generally high levels of support and feelings of worth as bases for effective coping at this age in particular. The underlying structure of both constructs, however, is well established to be multidimensional (Cauce et al., 1996; Harter, 1999). This suggests that differing sources of social support and self-esteem and their patterning across salient contexts of early adolescent development are an important consideration independent of the overall levels or availability of either type of resource (Bronfenbrenner, 1979; Magnusson, 1995). Of particular importance in this regard may be the degree of adaptive balance that is reflected in peer- versus adult-oriented sources of social support and self-esteem. Historically, theorists (e.g., Douvan \& Adelson, 1966) have emphasized the differentiated and often competing demands associated with peer- and adult-oriented contexts of adolescent development. Early adolescence in particular is characterized by intensified interest and concern with peer relations and associated areas of concern (e.g., body image) and yet by a continuing salient role for interactions with adults in settings such as school and family (Berndt \& Hestenes, 1996; Harter, 1999). Successful transition to full-fledged adolescence therefore may be 


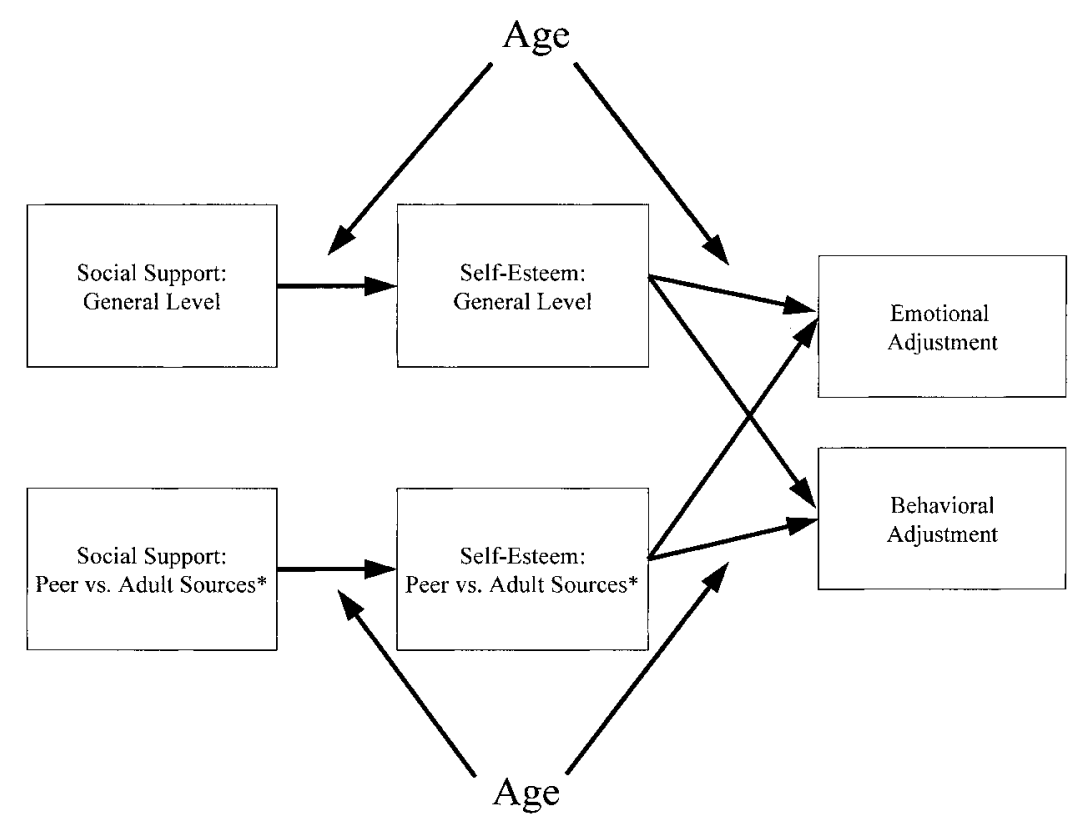

Figure 1. Conceptual framework for relations of social support and self-esteem to adjustment during early adolescence. *Relative strength of peer-oriented vs. adult-oriented sources of social support/self-esteem.

dependent on achieving greater intimacy and involvement with friends while at the same time handling significant new roles and responsibilities within the family and increasingly challenging demands in the school environment (Lerner et al., 1996).

In relevant empirical work, Harter and colleagues (see Harter, 1999) have distinguished between sources of support and selfesteem for young adolescents that are peer salient (i.e., peers, appearance, and athletics) or parent salient (i.e., schoolwork and behavioral conduct). DuBois and colleagues (DuBois, Bull, Sherman, \& Roberts, 1998; DuBois, Felner, Brand, \& George, 1999) similarly have distinguished profiles of early adolescent selfesteem that are peer oriented (i.e., emphasis on peer relations, appearance, and sports/athletics as bases for feelings of worth) or school/family oriented (i.e., emphasis on school and family relations). Seidman and colleagues (1999), furthermore, identified profiles of peer and family microsystem experiences for young adolescents that varied according to whether perceptions of support were stronger for peers or family members. Findings of the preceding studies suggest that young adolescents are more likely to experience problems in adjustment when sources of social support and self-esteem do not reflect a reasonably balanced representation across peer- and adult-oriented areas. A pattern of relatively strong peer-oriented sources of support or esteem in comparison with domains of school and family in particular has been found to be associated with greater levels of externalizing problems (DuBois, Bull, et al., 1998; DuBois et al., 1999; Seidman et al., 1999). Results are more equivocal with regard to risk for difficulties in emotional adaptation (e.g., depression). There is some evidence that adjustment problems in this area also can be associated with a contrasting pattern of relatively strong adult- versus peer-oriented sources for either self-esteem (DuBois et al., 1999) or social support (Seidman et al., 1999). It is important to note that existing studies have been predominantly cross-sectional in design. Longitudinal research is therefore needed to clarify potential contribu- tions of differing configurations of social support and self-esteem to adjustment outcomes over time during early adolescence.

\section{Self-Esteem as Mediator of Effects of Social Support}

Self-esteem has been proposed by many theorists to function as an intervening variable or process through which differing types of socioenvironmental experiences influence developmental outcomes (Connell, Spencer, \& Aber, 1994; Harter, 1999; Newcomb $\&$ Keefe, 1997; Sandler et al., 1989). There are a variety of mechanisms through which social support in particular may serve to enhance feelings of self-worth among children and adolescents and thus facilitate their emotional and behavioral adjustment (DuBois, Felner, Sherman, \& Bull, 1994). Significant esteemenhancing features of social support may include direct communication of approval from significant others (Harter, 1999) as well as more traditional instrumental and emotional support functions (Sandler et al., 1989; Short, Sandler, \& Roosa, 1996). Several considerations, furthermore, suggest an important role for selfesteem as a mediator of effects of social support specifically in early adolescence. Because of increasing capacities for abstract thought and self-reflection during this period, for example, there is a growing potential for experiences of support to be internalized in the form of self-system resources (Harter, 1999). Early adolescence is also characterized by a trend toward increased independence, including greater amounts of time spent alone (Larson, 1997). These changes may lead various sources of social support (e.g., parents) to become less directly influential in the lives of young adolescents and instead more likely to shape their adjustment outcomes indirectly. One way this may occur is by such ties enhancing resources (e.g., self-esteem) that youth then have available for coping in contexts outside of those relationships (Cauce et al., 1996). 
To the extent that these types of processes are salient, measures of social support should be linked significantly to indices of adjustment via their intermediary linkages with indices of selfesteem as mediators (Kenny, Kashy, \& Bolger, 1998). Measures of social support might or might not still contribute independently to prediction of indices of adjustment under these circumstances, depending on whether a residual direct effect of support on adjustment remains evident after taking into account mediational pathways involving self-esteem-that is, whether mediation is partial or complete (Holmbeck, 1997). Findings of prior crosssectional research are consistent with a social support $\rightarrow$ selfesteem $\rightarrow$ adjustment mediational pathway for older children and adolescents (for a review, see DuBois \& Tevendale, 1999). These results are based primarily on measures of overall levels of social support and/or self-esteem. Mediational pathways involving patterns of relative balance in these resources, although theoretically plausible (e.g., peer-oriented configurations of social support contributing to peer-oriented patterns in self-esteem), have not been investigated. It also is important to rule out alternative directions of influence in mediational hypothesis testing (e.g., effects of selfesteem on social support). To address this concern, mediational relations involving social support and self-esteem reported previously in the literature require further analysis using longitudinal data (Kenny et al., 1998).

\section{Moderating Effects of Age}

The preceding developmental considerations also suggest the potential for age-related shifts or changes in linkages of social support and self-esteem with adjustment as youth progress through the transitional period of early adolescence (see Figure 1). With respect to balance in sources of support and esteem, for example, peer-oriented patterns for each resource are likely to become more prevalent and, hence, normative in adolescence (Steinberg \& Morris, 2000). This, in turn, could lead such patterns or configurations to have fewer negative implications for adjustment. Likewise, to the extent that conditions conducive to a mediational role for self-esteem increase during early adolescence, effects of social support on adjustment through this type of mechanism could become more salient. In previous research, a possible moderating role for age or developmental status has been difficult to assess. The reasons for this include limited age ranges of youth within samples as well as a reliance on relatively short-term longitudinal designs (e.g., 6 months).

\section{Methodological Considerations}

Two further significant methodological issues also merit consideration. One is the predominant reliance on self-report measures in previous research investigating relations of social support and self-esteem to adolescent adjustment. Efforts to address this concern have focused on the use of multi-informant assessments of adjustment. Outside informants (e.g., parents), however, also may be able to provide useful perspectives on the supportiveness of youth's social relationships (Edens, Cavell, \& Hughes, 1999) as well as their self-evaluative tendencies (Marsh \& Craven, 1991). These latter data, if examined in combination with multi-informant indices of adjustment, could constitute a particularly rigorous approach to addressing shared informant variance as a source of bias in findings.
A second area of concern pertains to data analysis procedures when longitudinal data are available. Highly individualized patterns of change are characteristic of the early stages of adolescence (Lerner et al., 1996). It thus seems desirable to use a method that is sensitive to these differing rates of change and that incorporates them directly into models testing relations of social support and self-esteem to adjustment outcomes. Latent growth-curve modeling (LGM), a procedure that allows for estimation of within-person trajectories of change on variables, is one promising technique for addressing this concern (Willett \& Sayer, 1994). Most applications of this method within developmental research have been limited to analysis of relations that are evident between trajectories of change on at most two separate variables or constructs (e.g., social support and adjustment; see Willett, Singer, \& Martin, 1998). Recently, however, investigations have begun to expand such analyses to multiple constructs. These efforts include use of LGM procedures to test mediational models (Sandler, Tein, Mehta, Wolchik, \& Ayers, 2000). LGM thus has the potential to be useful in addressing the full range of theoretical concerns discussed previously, including the role of self-esteem in mediating relations of social support to adjustment in early adolescence.

\section{The Present Study}

The present study investigates social support and self-esteem as influences on adjustment during early adolescence using a 2-year, four-wave longitudinal design. LGM was used to enhance sensitivity to within-person patterns of change in social support, selfesteem, and adjustment over time. Measures assessed both general levels and relative balance in peer- versus adult-oriented sources for social support and self-esteem, along with internalizing (i.e., emotional) and externalizing (i.e., behavioral) problems in adjustment. Multi-informant data were obtained from youth and parents for all constructs, thus allowing both within-informant and crossinformant analyses to be conducted. Finally, the sample encompassed a relatively wide range of ages (i.e., ages $10-15$ years). This feature of study allowed for evaluation of a possible moderating role of developmental status on relations that social support and self-esteem exhibit with adjustment outcomes.

\section{Method}

\section{Sample}

Youth were selected randomly for possible participation from the public school system of a medium-sized Midwestern city (population 70,000). Selection was stratified to include approximately equal numbers of youth within relevant categories of each of the following demographic and background characteristics: gender, race/ethnicity (White and African American), grade level (Grades 5 and 6 vs. Grades 7 and 8 to represent youth at relatively early and later stages of transition to adolescence, respectively), and family low-income status (as indicated by a parentreported annual family income of $\$ 20,000$ or less). There was a further effort to balance selection across the different combinations of these characteristics (e.g., African American girls in Grades 5 or 6 from lowincome families). African American youth constituted only approximately $15 \%$ of the overall student population; one important aim of the stratified selection process therefore was to achieve a more equitable representation for these youth relative to White youth in the final sample. The participating school system provided the information necessary for selection on the basis of gender, race, and grade level but was not able to provide data on family income status. An alternative strategy therefore was used in which, 
on the basis of student address information and U.S. Census Bureau data, there was overselection of youth from areas (i.e., block groups) that had relatively greater concentrations of low-income families with school-age children; overselection was limited to 2 times the percentage representation of a given block group among the students attending the targeted grade levels, with students from all other, higher income areas also still sampled to help ensure sample representativeness. This indirect approach necessarily introduced a certain degree of imprecision into the sample selection process. As noted, the family low-income status of each participating youth ultimately was determined on the basis of parent-reported income obtained at the initial time of assessment.

A total of 350 youth participated in the initial assessment for the study in the fall of 1997 (Time 1). Follow-up assessments then occurred at 6-month intervals during the spring of 1998 (Time 2), fall of 1998 (Time 3), and spring of 1999 (Time 4). Youth were assessed on a rolling basis at Time 1 as they were recruited into the study from late September through December; to ensure appropriate periods of time between this and subsequent assessments, we collected follow-up data from each youth at 6-month intervals relative to his or her initial, Time 1 date of assessment. In general, the attrition rate was low, with approximately $90 \%$ of the original sample included in each follow-up assessment. Sample attrition was not cumulative but rather was specific to any given time point. There were several instances, for example, in which youth missed one follow-up assessment (e.g., Time 2) but then reentered the study at a later time point (e.g., Time 3). In addition, parent-report data were able to be obtained for approximately $90 \%$ of those youth who participated at any given time point.

The overall sample included 170 boys and 180 girls, 160 White and 190 African American youth, 189 youth in Grades 5 and 6 and 161 youth in Grades 7 and 8, and 173 youth from low-income families and 177 from non-low-income families. In accordance with sampling goals, youth generally were distributed in comparable (i.e., approximately equal) numbers across differing combinations of the preceding demographic characteristics. There was, however, a substantially greater number of African American youth from low-income families $(n=$ 113) than White youth from low-income families $(n=60)$, which resulted in a significant association between race and family lowincome status within the sample, $\chi^{2}(1, N=350)=16.78, p<.001$. Finally, in terms of age, youth at Time 1 ranged from 10 years old to 15 years old $(M=11.86$ years; $S D=1.22)$.

\section{Procedure}

Participation was voluntary and required both parent or guardian consent and youth assent. Following an initial mailing describing the study, we contacted parents and youth by phone and, when necessary, by home visits. Transportation to questionnaire sessions was offered to reduce obstacles to participation among youth from low-income families. In addition, research team members from minority backgrounds were involved as much as possible in making initial contacts with African American youth and their parents. Youth were informed that they would receive $\$ 12$ compensation for completion of study measures at each time point of the study; parents similarly were informed that they would receive $\$ 5$ compensation. Using these procedures, we obtained consent for participation for approximately $60 \%$ of youth who were selected and able to be contacted. This rate compares favorably with prior research involving youth from similar demographic backgrounds (see, e.g., Seidman et al., 1999).

Questionnaires were administered to youth during 2-hr group sessions at the university laboratory facilities of David L. DuBois; individually scheduled sessions also took place at the same location as necessary. During sessions, the instructions and items for each instrument were read aloud to ensure that reading level did not interfere with accurate completion of measures. Youth indicated their responses on questionnaire forms. Every effort was made to ensure that in doing so, they experienced a sense of privacy from both other youth and research staff. Consistent with this aim, youth were assured repeatedly of the confidentiality of their responses within ethical guidelines; in addition, each youth's forms were identified with a unique number rather than his or her name. A small number of youth moved out of the local area during the course of the study. For these youth, arrangements were made for questionnaires to be completed either by mail or by telephone interview.

Measures also were completed at each time of assessment by a parent or guardian as well as one of the youth's teachers at school. Data obtained from parents, but not teachers, are used in the present investigation. Parent questionnaires in a majority of instances were completed by the youth's mother $(79 \%$ at Time $1 ; 79 \%$ at Time $2 ; 81 \%$ at Time $3 ; 82 \%$ at Time 4$)$. Comparison of ratings provided by mothers with those of fathers and other parental figures for measures used in the current study failed to reveal systematic differences at any of the four time points.

\section{Measures}

Study measures assessed youth social support, self-esteem, and internalizing and externalizing problems. In accordance with the multiinformant design of the research, each construct was assessed separately using both youth- and parent-report data at all four time points of the study.

Social support. Ratings of social support from youth were obtained using a modified version of the Perceived Social Support Scale (Procidano $\&$ Heller, 1983). The modified measure (DuBois, Felner, Sherman \& Bull, 1994) consists of 30 items and yields separate scores for levels of perceived social support received from family, peers, and school personnel, respectively. Each item is a declarative statement (e.g., "My family notices and gives me help when I need them to"), which the respondent is asked to rate on a 3-point scale (no, sometimes, yes). Each scale score is derived by summing the 10 items that refer to that source of support (i.e., family, peers, or school personnel), with items scored 0 to 2 in the direction of higher support. Prior research has provided support for the reliability and validity of scores on the revised measure (DuBois, Felner, Brand, Phillips, \& Lease, 1996; DuBois, Felner, Sherman, \& Bull, 1994). For the present sample, internal consistency reliability (coefficient alpha) for scale scores ranged from .78 to .87 at Time 1 , from .81 to .89 at Time 2 , from .81 to .87 at Time 3, and from .83 to .90 at Time 4 . Correlations among the scales assessing support from the three different sources at each time point were moderate (mean $r$ s ranged from .32 to .37 ).

In accordance with aims of the research described previously, we used scores on the measure to derive separate measures addressing general social support and balance in peer- versus adult-oriented sources of support, respectively. The general social support measure was derived by taking the mean of the three scale scores at each time point. To derive a measure addressing relative balance in sources of social support, first we standardized and averaged scores on the family and school personnel scales to form a composite of ratings for adult-oriented sources of support. The peers social support scale score on the measure then was regressed on this composite such that positive values for the residual term indicated scores in the direction of ratings of peer-oriented social support being relatively more favorable than would be predicted on the basis of ratings of adultoriented sources of support and vice versa for negative values. Next, this process was reversed, such that the adult composite measure was regressed on the peer scale score. This second residual term was inverted (i.e., multiplied by -1 ) so that scores were in a direction comparable to those of the first residual term, and then the two residual terms were averaged to yield a single measure for use in the study. Higher scores on the measure thus reflected ratings for peer-oriented sources of social support that were relatively strong (i.e., favorable) in comparison with those for adultoriented sources and vice versa for lower scores. The process of doubly residualizing scores in the manner described was designed to avoid a disproportionate or unequal degree of overlap between either of the respective indices of adult- and peer-oriented social support on the one hand 
and the resulting measure addressing balance in these sources of support on the other hand. ${ }^{1}$

Parent ratings of social support were obtained using a parent-report version of the preceding measure (DuBois, Brooks, Davis, Gok, \& Odum, 1998). This measure consists of five items for each source of support with items reworded to make them appropriate for parental rating (e.g., the item "My family enjoys hearing about what I think" is changed to "This child's family enjoys hearing about what he/she thinks"). For the present sample, these scores demonstrated strong internal consistency (alphas ranging from .81 to .92 ) and moderate intercorrelations (mean $r$ s ranging from .32 to .34). Separate measures addressing general social support and balance in peer- versus adult-oriented sources of support were derived in the same manner as described for youth-report data.

Self-esteem. The Self-Esteem Questionnaire (SEQ; DuBois et al., 1996), a self-report measure for older children and young adolescents, was used to obtain youth ratings of self-esteem. The SEQ consists of 42 items, each rated on a 4-point scale ranging from strongly disagree to strongly agree. The measure yields scale scores for self-evaluations pertaining to each of five separate domains (peer relations [8 items], school [8 items], family [8 items], physical appearance [4 items], and sports/athletics [6 items]), as well as global self-esteem ( 8 items). To ensure consistency with previous conceptualizations of the self-esteem construct (see, e.g., Brinthaupt \& Erwin, 1992), items used to assess self-evaluations in differing domains are stated so as to refer explicitly to degree of satisfaction or dissatisfaction with the aspects of the self that are described (e.g., "I feel OK about how good of a student I am" or "I am as good as I want to be at making new friends"). The global self-esteem scale consists of items that assess overall perceptions of self-worth (e.g., "I am happy with myself as a person"). Support for the reliability and validity of the SEQ has been reported in prior research (DuBois et al., 1996; see also DuBois, Bull, et al., 1998; DuBois et al., 1999; DuBois, Felner, Sherman, \& Bull, 1994). For the present sample, estimates of internal consistency for scale scores ranged from .65 (sports/athletics) to .86 (school) at Time 1 (mean $\alpha=.78$ ), from .60 (sports/athletics) to .85 (school) at Time 2 (mean $\alpha=.78$ ), from .69 (sports/athletics) to .87 (school) at Time 3 (mean $\alpha=.79$ ), and from .71 (sports/athletics) to .87 (school) at Time 4 (mean $\alpha=.82$ ).

In a manner paralleling that for social support, we computed separate measures addressing general self-esteem and balance in peer- versus adultoriented sources of self-esteem. Specifically, we averaged all scales on the SEQ to derive a measure of general self-esteem at each time point. To derive the measure addressing relative balance in sources of self-esteem, standardized scores on the family and school scales of the SEQ first were averaged to form an adult-oriented composite, as were scores on the remaining scales (i.e., peer relations, physical appearance, and sports/ athletics) to form a peer-oriented composite. It should be noted that items on the school scale of the SEQ refer exclusively to feelings about academic effort and performance; consequently, they reflect concern with schoolrelated issues of primary concern to adults (i.e., teachers and parents) as opposed to those that could be viewed as more peer oriented (e.g., relations with classmates). The decision to combine the peer scale of the SEQ with the physical appearance and sports/athletic scales to form a composite measure of peer-oriented sources of self-esteem is consistent with prior empirical work (DuBois, Bull, et al., 1998; Harter, 1999). Preliminary findings confirmed a substantial degree of intercorrelation among the three scales in the present sample (i.e., mean $r$ s ranging from .42 to .48 across the four time points). Scores on the resulting two SEQ composites (i.e., adultand peer-oriented) were compared with one another using the same double residualization process used in the derivation of the corresponding measure for social support and subsequently combined in the same manner to form a single index. Higher scores on the resulting measure reflected ratings for peer-oriented sources of self-esteem that were relatively strong (i.e., favorable) in comparison with those for the adult-oriented domains of school and family and vice versa for lower scores.

The Child Self-Esteem Questionnaire (CSEQ; DuBois, 1993), an abbreviated parent-report version of the SEQ, was used to obtain ratings of self-esteem from parents. The CSEQ contains 24 items, with 4 items used to assess each of the five domains of self-evaluation targeted on the SEQ as well as a separate 4-item scale for global self-esteem. Items parallel those on the SEQ, with wording changed to make them appropriate for parental rating (e.g., the item "I feel that I do not have much to be proud of" is changed to "This child feels that he/she does not have much to be proud of"). Parent-report scores on an earlier version of the CSEQ were found to demonstrate convergent and discriminant validity with self-report ratings of youth on the SEQ (DuBois et al., 1996). For the present sample, scale scores on the measure exhibited strong internal consistency (alphas .79 or greater across all time points). Separate measures addressing general self-esteem and balance in peer- versus adult-oriented sources of selfesteem were derived using the same procedures described previously for youth ratings.

Internalizing and externalizing problems. Youth and parent ratings of internalizing and externalizing problems were obtained using the Internalizing and Externalizing scales of the well-validated Youth Self-Report (Achenbach, 1991b) and Child Behavior Checklist (Achenbach, 1991a). The Internalizing scale includes items tapping depression, anxiety, social withdrawal, and somatic complaints, whereas the Externalizing scale includes items focusing on aggression and delinquent behavior. For the present sample, each of these scales had high internal consistency for both youth-report data (alphas of .89 or greater across the four time points) and parent-report data (alphas .88 or greater).

In accordance with recommended procedure (Achenbach, 1991a, 1991b), we used raw scores on the relevant scales of each measure in primary study analyses. It was of interest, however, to examine the proportion of youth in the sample at each time point for whom standardized scale scores were at or above levels indicating clinical significance (i.e., $T$ score $>64)$. At the initial time point, ratings were in the clinical range for between $17 \%$ and $26 \%$ of the sample depending on the scale and informant involved $(17.3 \%$ and $19.7 \%$ for youth-reported internalizing and externalizing problems and $24.9 \%$ and $25.6 \%$ for corresponding parent-report scales). Similar proportions of youth were found with ratings of problems in the clinical range at other time points. The relatively high prevalence of elevated ratings of adjustment problems within the sample may be a reflection in part of the large proportion of youth from socioeconomically disadvantaged backgrounds.

\section{Plan of Analysis}

Preliminary analyses examined intercorrelations among measures of social support, self-esteem, and adjustment at each time point, as well as stability correlations over time for each measure. In addition, LGM was used to fit basic models of change for each individual study measure over the four time points of the study.

In primary study analyses, we used a combination of LGM and covariance structure analysis to evaluate a model specifying hypothesized rela-

\footnotetext{
${ }^{1}$ Consistent with the intended effects of the double residualization procedure, higher scores on the resulting measure of peer versus adult sources of social support exhibited correlations of comparable magnitude in expected positive and negative directions, respectively, with the indices of peer support (mean $r=.60$ across the four time points) and school/ family support (mean $r=-.50$ ). By contrast, each of the separate residual terms referred to in the text was, on the one hand, by definition uncorrelated with the measure used as the predictor in the relevant residualization process (Pedhazur, 1997) and, on the other hand, found to exhibit strong correlations with the designated criterion measure (e.g., $r \mathrm{~s}>.80$ ). Thus, although they were correlated with each other (mean absolute $r=.39$ across the 4 time points), use of either residual term alone would have resulted in disproportionate overlap with one of the two component measures of support (i.e., peers or school/family composite). Similar results were obtained for the residualization-based measure addressing peer versus adult balance in sources of self-esteem also used in the research.
} 
tions among growth-curve parameters for measures of social support, self-esteem, and adjustment. Differing combinations of youth and parent informant data were used in these analyses. Within-informant analyses used either youth-report or parent-report measures of both social support/ self-esteem and adjustment problems. Cross-informant analyses used either youth-report measures of social support/self-esteem and parent-report measures of adjustment or, alternatively, parent-report measures of social support/self-esteem and youth-report measures of adjustment. Further analyses investigated age as a potential moderator of model fit and path estimates.

To minimize bias associated with attrition and missing data, we used the expectation maximization (EM) algorithm to estimate the maximum likelihood (ML) covariance matrices and mean vectors used as input for all LGM and structural modeling analyses. The EM algorithm is a useful technique for estimating ML covariance matrices and mean vectors in the presence of missing data. This approach to missing data estimation assumes that the data are missing completely at random or missing at random (Little \& Rubin, 1987). However, even if these assumptions are not met, EM (ML) parameter estimates still are typically less biased than those estimated with ad hoc procedures (e.g., pairwise or listwise deletion of missing data; see, e.g., Muthen, Kaplan, \& Hollis, 1987). A program developed by Gregorich (2001) was used to implement the EM algorithm for present purposes. All LGM and covariance structure analyses were conducted using Version 5.1 of EQS structural equation modeling software (Bentler, 1996).

\section{Results}

\section{Zero-Order Correlations}

Zero-order correlations for primary study measures at each time point, as well as stability correlations over time for each measure, are shown in Table 1. The two types of measures of social support (i.e., general and peer vs. adult sources) exhibited a relatively weak, negative association at each time point for youth-report data (mean $r=-.18$ ), indicating a tendency for greater overall ratings of social support to be associated with relatively more favorable ratings for adult- in comparison with peer-oriented sources of support; corresponding associations for parent-report measures of social support were nonsignificant (mean $r=-.09$ ). Similarly, the two types of measures of self-esteem were not related significantly at any time point for either informant (mean $r$ s of .07 and .06 for youth- and parent-report, respectively). Measures of social support exhibited a moderate association with corresponding measures of self-esteem at each time point (e.g., social support-general with self-esteem-general), when considering both youth-report data (mean $r$ s of .42 for general and .23 for peer vs. adult sources) and parent-report data (mean $r$ s of .49 and .25 , respectively). Correlations across youth and parent informants for each measure of social support also were significant at each time point (mean $r \mathrm{~s}$ of .25 for general and .23 for peer vs. adult sources), as were those for measures of self-esteem (mean $r$ s of .30 and .38 , respectively). These associations were stronger than cross-informant associations involving corresponding measures of social support and selfesteem (e.g., youth-reported general social support and parentreported general self-esteem; mean $r$ s of .19 for general and .10 for peer vs. adult sources). Overall, findings thus were consistent with examining social support and self-esteem as distinct but related constructs in primary study analyses. Results, furthermore, indicated the relative independence of the two types of measures (i.e., general and peer vs. adult sources) used to assess differing facets of each construct.
Measures of internalizing and externalizing problems derived from the same informant exhibited a substantial degree of association at each time point ( $r$ s ranging from .61 to .71 for youth ratings and from .54 to .58 for parent ratings). Cross-informant associations, however, again provided support for discriminant validity (i.e., average $r=.31$ when both youth and parents were rating either internalizing or externalizing problems compared with average $r=.16$ for associations across informants between ratings of internalizing problems and externalizing problems).

The general measures of social support and self-esteem were related in the expected negative direction to indices of both internalizing and externalizing problems at each time point. These associations were strongest on a within-informant basis (i.e., when measures of social support/self-esteem and adjustment each were obtained from the same informant). Nevertheless, they were evident and generally significant on a cross-informant basis as well (e.g., youth-report measures of social support/self-esteem and parent-report measures of adjustment). Measures of relative balance in peer- versus adult-oriented sources of social support and self-esteem also exhibited significant associations with indices of adjustment. These primarily involved positive associations between scores on the measures and indices of externalizing problems, thus indicating that relatively more favorable ratings for peer- in comparison with adult-oriented sources of each resource tended to be associated with reports of greater adjustment difficulties in this domain.

As shown in Table 1, individual measures exhibited moderate to strong stability across adjacent time points (mean $r$ s ranging from .45 for parent-report measure of peer vs. adult sources of social support to .78 for parent-reported externalizing problems). These associations, however, accounted for no more than approximately $60 \%$ of the observed variance over time on any given measure.

\section{Latent Growth-Curve Models for Individual Measures}

For each of the growth models fit for individual study measures, we hypothesized that observed scores at the four time points were influenced by two latent factors: (a) the initial status or intercept factor, which reflects the level of the variable at a fixed occasion of measurement, and (b) the linear rate of change factor. For these models, the initial status or intercept in all instances was defined as Time 1. In addition, the covariance between initial status and linear rate of change factors was estimated in each model. To capture effects of age, we also included age of participants (in years) as an exogenous variable in all models that could influence both initial status and rate of change in the variable over time; age was centered around the sample mean age to facilitate interpretation of findings for this variable (Willett \& Sayer, 1994). Finally, we conducted tests in each model to determine whether fit could be improved by allowing for a quadratic rate of change. Following prior research (Sandler et al., 2000), we accomplished this by fitting a fixed quadratic model of change in which participants were assumed to demonstrate a common rate of acceleration/ deceleration (analyses exploring a nonfixed quadratic model either indicated nonsignificant variability in the quadratic rate of change across participants or failed to yield a technically proper solution).

As shown in Table 2, a latent growth model with an acceptable level of overall fit was obtained for each study measure according to several criteria. These included relatively low ratios of $\chi^{2}$ to degrees of freedom, values of comparative fit index (CFI) and 
DuBOIS ET AL.

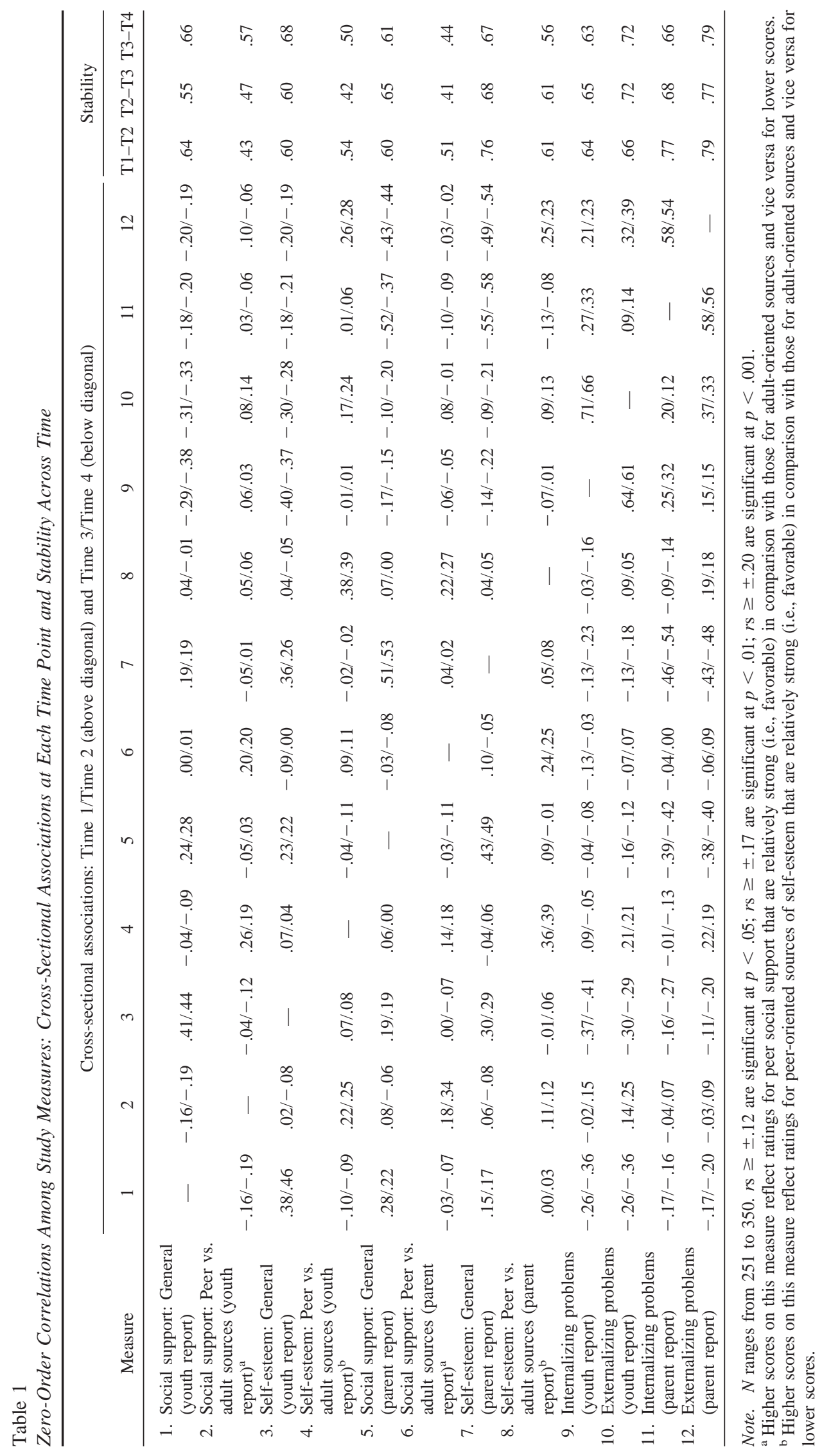




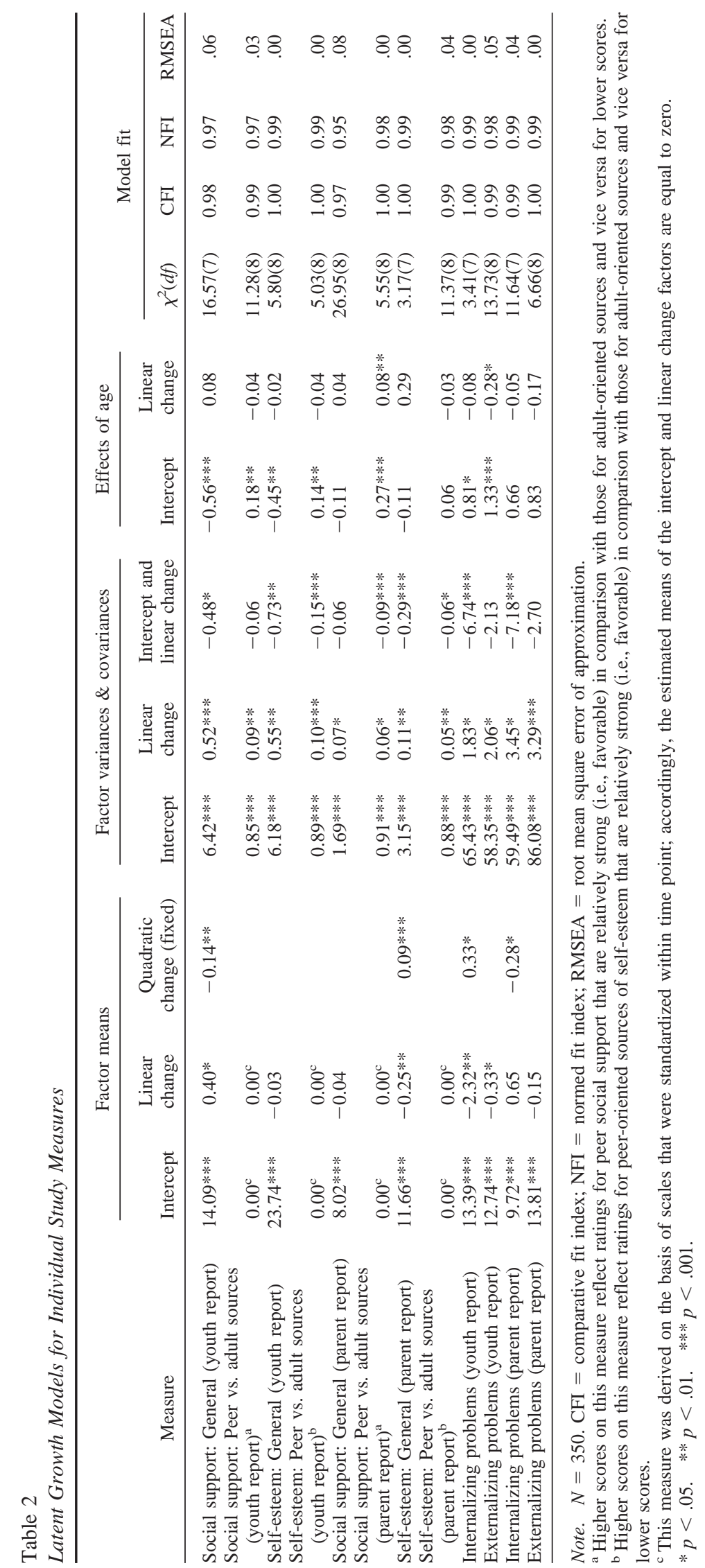


normed fit index greater than .90 , and a root mean square error of approximation of less than .10 (Bollen, 1989). For four measures (i.e., youth-reported general social support, parent-reported general self-esteem, and youth- and parent-reported internalizing problems), the final model included a significant fixed quadratic effect. Inspection of the curvilinear trends for these measures revealed that, on average, growth curves for youth-reported general support reflected a pattern of increase in overall perceptions of support across the first three time points of the study (i.e., Time 1 to Time 3) but a decline from Time 3 to Time 4 . For parentreported general self-esteem, there was, on average, a decrease from Time 1 to Time 2, followed by an increase during the remainder of the study (i.e., Time 2 to Time 4). For internalizing problems, youth-report data reflected a trend of decline during the first three time points, followed by a leveling off from Time 3 to Time 4; parent-report data followed a pattern of slight increase from Time 1 to Time 2, decline from Time 2 to Time 3, and, again, a leveling off from Time 3 to Time 4 .

There also were effects of age for several measures. These included significant age differences in both intercept and linear rate of change parameters for growth curves (see Table 2). Significant age effects on intercept included findings in the direction of lower levels of youth-reported general social support and general self-esteem for older youth. There also were significant positive effects of age on intercept for youth-report measures addressing peer versus adult sources of support and esteem. These indicate that older youth had higher initial estimated scores on these measures, such that their ratings for peer-oriented sources of social support and self-esteem tended to exceed those for adult-oriented sources to a greater degree than was the case for younger youth. The absence of age differences in estimates of linear change for these measures, furthermore, indicates that the tendency for older youth to report relatively more peer-oriented sources of support and esteem was sustained over the remainder of the study. There was a similar positive effect of age on intercept for the parentreport measure of peer versus adult sources of self-esteem. For this measure, there also was a significant positive effect of age on the linear change parameter. This finding indicates that growth curves for older youth showed a tendency for ratings of sources of self-esteem to increase in their peer orientation at a greater rate over time, thus widening the gap between younger and older youth on this measure during the course of the study.

As shown in Table 2, there was significant variability in both intercept and linear change parameters of growth curves for each measure. This indicates a substantial degree of variation in both levels and rates of change over time on study measures among youth within the sample. This variation is of critical importance for purposes of the present study in which the focus is on investigating relations among estimated growth-curve parameters for differing measures. To avoid problems of restricted range in these types of analyses, significant variation needs to be present in relevant growth parameters at the level of the overall sample (Willett \& Sayer, 1994).

\section{Latent Growth-Curve Modeling Analyses of Relations of Social Support and Self-Esteem to Adjustment}

Overview of analyses. As noted previously, primary study analyses used a combination of LGM and covariance structure analysis to investigate models of relations among growth param- eters for measures of social support, self-esteem, and adjustment. To allow for examination of independent effects of overall levels and relative balance in peer versus adult sources for social support and self-esteem, we included growth parameters for both facets of these constructs together in each model. Each model also included growth parameters for both internalizing and externalizing problems. Intercept factors for measures of social support, self-esteem, and adjustment ${ }^{2}$ were defined at Time 1 , Time 3, and Time 4, respectively. ${ }^{3}$ This was accomplished by fixing the respective linear change or slope factor loadings for observed measures at first, third, and fourth occasions of measurement to zero. As a consequence of this scaling of the time metric, the intercept factors can be thought of as the expected levels of social support, selfesteem, and adjustment measures at first, third, and fourth occasions of measurement, respectively (Willett \& Sayer, 1994). This scaling approach follows that used previously by Sandler and colleagues (2000) in their use of LGM to test a mediational model. For present purposes, it was selected for two reasons. First, it ensured temporal precedence of intercept factors for social support relative to those for self-esteem in accordance with the hypothesized mediational status of self-esteem (Kenny et al., 1998). Second, it ensured temporal precedence of both types of predictors to intercept factors for criterion indices of adjustment. If a measure had been revealed to have a significant fixed quadratic growth component in earlier LGM analyses, it also was included. For these measures, the linear change or slope parameter could be interpreted as the instantaneous rate of change at the point in time when the intercept factor was defined (Sandler et al., 2000). Furthermore, any age effects on growth parameters found to be significant in previous LGM analyses were included to control for these associations.

Structural paths among growth parameters were estimated in accordance with previous use of LGM procedures in testing mediational models (Sandler et al., 2000). This involved estimating paths representing effects of social support growth parameters on self-esteem growth parameters and self-esteem growth parameters, in turn, on those for measures of adjustment. Specifically, the Time 3 intercept factor for each self-esteem measure was modeled as being influenced by the Time 1 intercept factor for the corresponding social support measure (i.e., general or peer vs. adult sources) as well as by the linear rate of change factor for that support measure; the rate of growth factor for each self-esteem measure was modeled as being influenced only by the rate of change factor for the corresponding social support measure. Similarly, the Time 4 intercept factor for each measure of adjustment was modeled as being influenced by the intercept and linear rate of

\footnotetext{
${ }^{2}$ The intercept factors for measures of self-esteem and adjustment had been defined previously at Time 1 in the LGM analyses conducted for individual measures. Consequently, before proceeding with the use of intercept factors at different time points for these measures in primary study analyses, we refit the separate growth-curve models for each measure using the alternative time points for intercepts. These analyses revealed continued satisfactory levels of model fit. Furthermore, the key condition of significant variance in intercept and linear change (rate of growth) parameters was still met for all measures.

${ }^{3}$ Means of the intercept and linear change factors for measures addressing peer versus adult balance in sources of social support and self-esteem were fixed at zero for these analyses on the basis of prior results and scoring procedures for the measures (see Table 2).
} 
change factors for both types of measures of self-esteem, whereas rate of change for each adjustment measure was predicted only by the rate of change factors for self-esteem measures. Within respective portions of the model that pertained to social support, selfesteem, or adjustment, covariances among all factors (or, equivalently, factor residual terms when appropriate) in that portion of the model were estimated; similarly, covariances among errors for measures associated with a given time point also were estimated in each portion of the model.

Within-informant analyses. Results of within-informant analyses, in which either youth-report or parent-report measures were used for both social support/self-esteem and adjustment problems, are shown in Figure 2. The model fit using youth-report data has an acceptable overall fit (e.g., CFI $=.95)$ and includes numerous significant paths linking both social support to self-esteem and self-esteem to adjustment (hypothesized paths that did not reach or approach significance were included in all models but are not depicted in the figures for the sake of clarity). With regard to support and esteem, the general social support Time 1 intercept factor was a significant predictor of the general self-esteem Time 3 intercept factor (unstandardized path coefficient $[b]=.52, p<$ $.001)$; the factor representing rate of linear change in general social
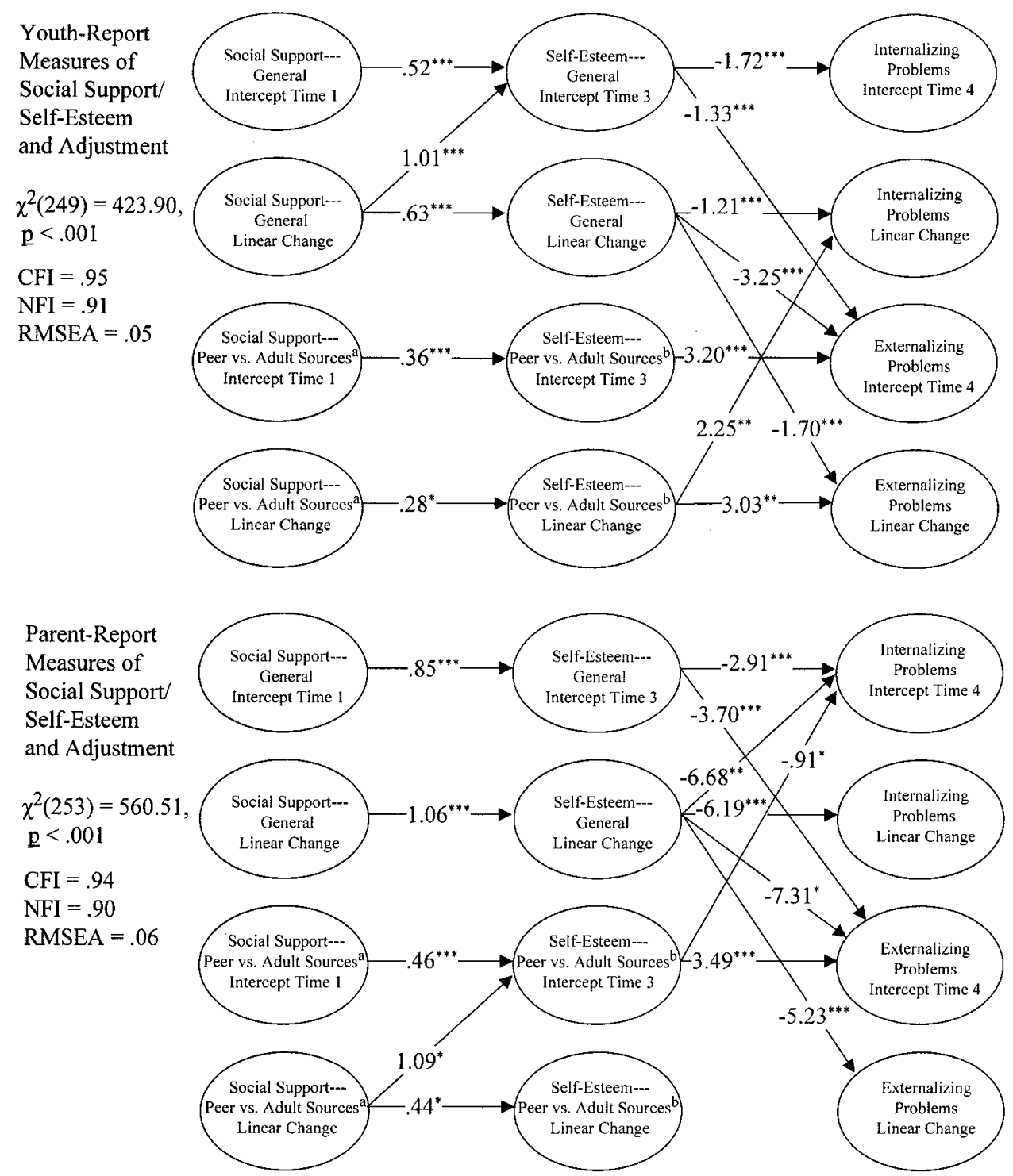

Figure 2. Structural models for within-informant analyses $(N=350)$. Path coefficients are unstandardized, and significance levels were determined by critical ratios on unstandardized coefficients $\left({ }^{*} p<.05 ; * * p<.01\right.$; $* * * p<.001)$. Hypothesized paths that did not reach or approach significance were included in both models but are not depicted for the sake of clarity. CFI = comparative fit index; NFI = normed fit index; RMSEA = root

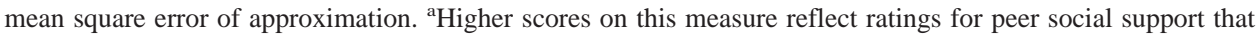
are relatively strong (i.e., favorable) in comparison with those for adult-oriented sources and vice versa for lower scores. ${ }^{b}$ Higher scores on this measure reflect ratings for peer-oriented sources of self-esteem that are relatively strong (i.e., favorable) in comparison with those for adult-oriented sources and vice versa for lower scores. 
support also predicted both Time 3 intercept and rate of change factors for general self-esteem in a positive direction $(b \mathrm{~s}=1.01$ and .63, respectively, $p$ s $<.001)$. Similarly, the Time 1 intercept factor for peer versus adult sources of social support predicted the Time 3 intercept factor for peer versus adult sources of self-esteem ( $b=.36, p<.001)$; in addition, rate of change for peer versus adult sources of social support predicted rate of change for the peer versus adult sources of self-esteem $(b=.28, p<.05)$. With regard to self-esteem and adjustment, the general self-esteem Time 3 intercept factor was a significant predictor in the expected negative direction of Time 4 intercept factors for both internalizing problems and externalizing problems $(b \mathrm{~s}=-1.72$ and -1.33 , respectively, $p$ s $<.001)$. Rate of change in general self-esteem also exhibited the expected inverse predictive relations with rate of change in internalizing problems $(b=-1.21, p<.001)$ and with both Time 4 level and rate of change factors for externalizing problems $(b s=-3.25$ and -1.70 , respectively, $p s<.001)$. In addition, peer versus adult sources of self-esteem at Time 3 predicted level of externalizing problems at Time 4 in a positive direction $(b=3.20, p<.001)$. This finding indicates that reports of relatively strong peer-oriented sources of self-esteem were predictive of greater reported levels of externalizing problems at the later time point. Rate of change for peer versus adult sources of self-esteem, furthermore, was related in the same direction to rate of change for externalizing problems $(b=3.03, p<.01)$ as well as to rate of change for internalizing problems $(b=2.25, p<$ $.01)$.

The model fit using parent-report data also has an acceptable overall fit (e.g., CFI $=.97$ ) and includes generally the same types of significant paths (see Figure 2). The primary difference is that peer versus adult sources of self-esteem now are linked in a contrasting, negative direction to internalizing problems. This is evident in the form of a significant path from Time 3 level of the measure to Time 4 level of internalizing problems $(b=-.91, p<$ $.05)$. Thus, relatively strong adult-oriented, rather than peeroriented, sources of self-esteem were now predictive of greater internalizing problems. Imbalance in the direction of relatively strong peer-oriented sources of self-esteem did, however, continue to predict greater externalizing problems as indicated by the significant path linking Time 3 and Time 4 intercept factors for these measures, respectively $(b=3.49, p<.001)$.

To summarize briefly, in both types of within-informant analyses, the hypothesized model provides a good fit to the data and includes numerous significant structural paths among growth parameters for measures of social support, self-esteem, and adjustment. Findings include significant paths involving growth parameters for measures of both general and peer versus adult sources of social support and self-esteem. As predicted, the paths found follow a pattern in which growth parameters for each facet of social support (i.e., general level and relative balance in peer vs. adult sources) are linked positively to growth parameters for the corresponding facet of self-esteem, with the latter parameters then being linked to growth parameters for measures of adjustment in generally expected directions.

Cross-informant analyses. Results of analyses using crossinformant data are shown in Figure 3. It can be seen that overall model fit is acceptable both when using youth-report measures of social support/self-esteem and parent-report measures of adjustment (e.g., $\mathrm{CFI}=.96$ ) and when using parent-report measures of social support/self-esteem and youth-report measures of adjust- ment (e.g., CFI $=.97)$. In each instance, there are several significant paths linking self-esteem and adjustment factors now based on data from differing informants. All paths involving level and rate of change factors for general self-esteem are in the expected negative direction. Illustratively, as shown in the top portion of Figure 3, youth-reported level of general self-esteem at Time 3 predicted lower parent-reported levels of internalizing and externalizing problems at Time $4(b \mathrm{~s}=-.98$ and -.99 , respectively, $p \mathrm{~s}<.001)$; in a corresponding manner, as shown in the bottom portion of Figure 3, parent-reported level of general self-esteem predicted lower subsequent levels of youth-reported internalizing and externalizing problems $(b \mathrm{~s}=-.85$ and -.90 , respectively, $p$ s $<.01)$. With respect to balance in sources of self-esteem, for the model based on youth-report measures of social support/selfesteem and parent-report measures of adjustment, there are again significant paths linking imbalance in the direction of relatively strong peer-oriented sources of self-esteem to greater externalizing problems. Paths relating peer versus adult balance in sources of self-esteem to internalizing problems also are evident but continue to be mixed in direction across differing analyses (see Figure 3).

In summary, results of cross-informant analyses again indicate an acceptable fit for the overall hypothesized model. Relative to analyses based on within-informant data, structural paths are somewhat less numerous but continue to follow the same generally expected pattern. Most notably, growth parameters for general level and peer versus adult sources of self-esteem continue to be linked to growth parameters for measures of adjustment, despite the two types of measures now being based on differing informants.

Self-esteem as mediator of relations of social support with adjustment. The preceding findings are consistent with selfesteem mediating relations of social support with adjustment (i.e., social support $\rightarrow$ self-esteem $\rightarrow$ adjustment). When conducting mediational hypothesis testing in the context of structural equations modeling, however, it is important to also evaluate the overall statistical significance of each potential mediational chain of influence. ${ }^{4}$ To meet all criteria for mediation, it is furthermore necessary to evaluate each mediational chain in a model that includes a path representing the direct influence of the originating, predictor variable on the criterion variable (Kenny et al., 1998). In the present context, we evaluated potential mediational chains after adding the relevant direct paths to the structural models fit previously. For the within-informant model based on youth data, for example, this included testing the mediational chain in which the Time 1 intercept factor for general social support was related to the Time 4 intercept factor for internalizing problems via a pathway occurring through the Time 3 intercept factor for general selfesteem. It will be recalled that the hypothesized model includes

\footnotetext{
${ }^{4}$ Mediational chains were evaluated on the basis of tests of relevant indirect effects of social support on adjustment that occurred via intermediary linkages with self-esteem within each structural model (Bollen, 1989). Although the term indirect effects is sometimes used interchangeably with the concept of mediation, various reasons suggested that it was not appropriate to do so in the present context. Effects-oriented terminology may imply causal inference, for example, despite the inherently correlational nature of the associations involved. Given such considerations, only the term mediational chain is used in the present article when referring to results of tests of what are commonly also referred to as indirect effects in structural modeling analyses.
} 


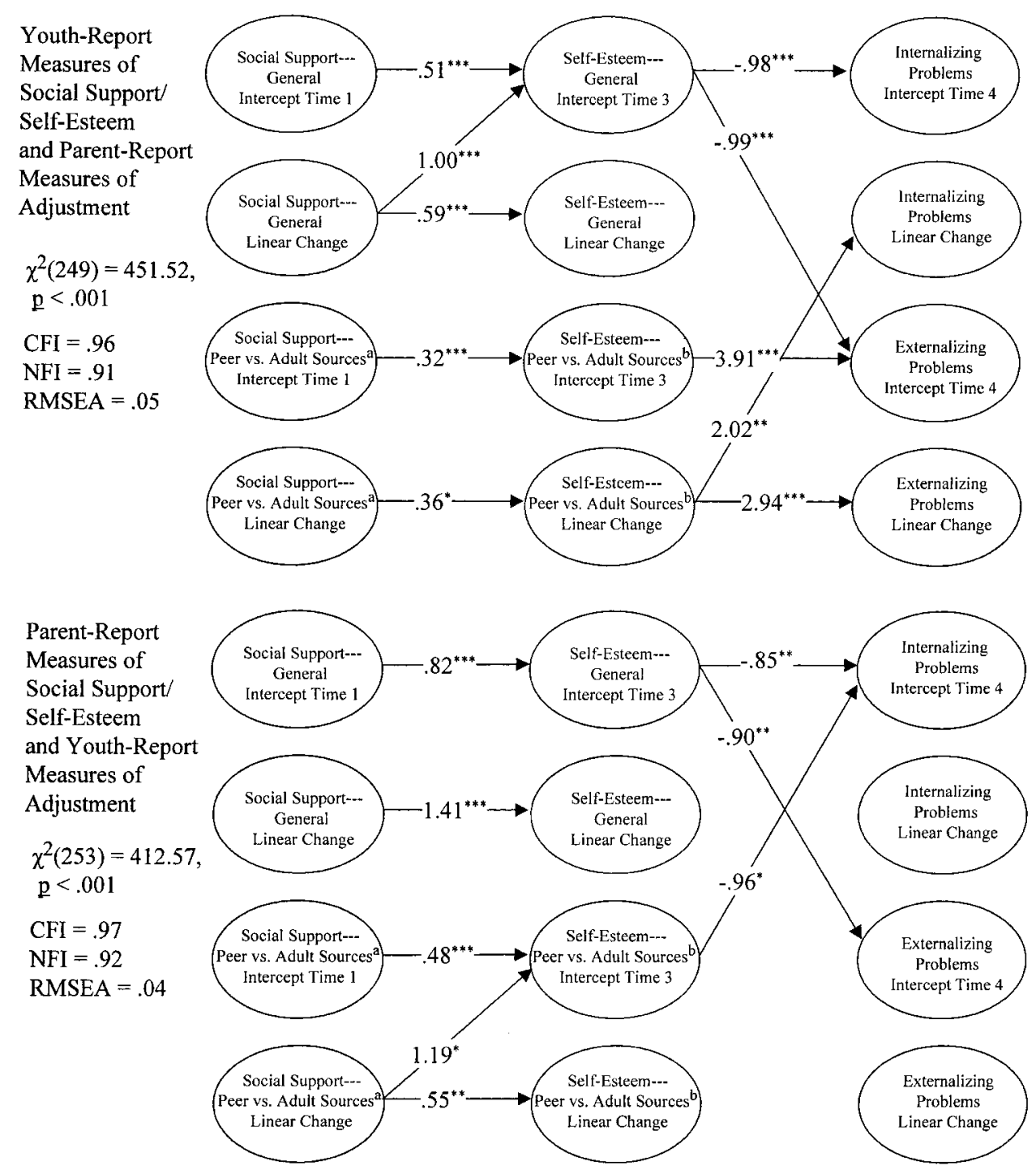

Figure 3. Structural models for cross-informant analyses $(N=350)$. Path coefficients are unstandardized, and significance levels were determined by critical ratios on unstandardized coefficients $\left({ }^{*} p<.05\right.$; $*^{*} p<.01$; $* * * p<.001$ ). Hypothesized paths that did not reach or approach significance were included in both models but are not depicted for the sake of clarity. CFI = comparative fit index; NFI = normed fit index; RMSEA = root mean square error of approximation. ${ }^{a}$ Higher scores on this measure reflect ratings for peer social support that are relatively strong (i.e., favorable) in comparison with those for adult-oriented sources and vice versa for lower scores. ${ }^{b}$ Higher scores on this measure reflect ratings for peer-oriented sources of self-esteem that are relatively strong (i.e., favorable) in comparison with those for adult-oriented sources and vice versa for lower scores.

paths linking the rate of change growth factor for each measure of social support to both intercept and rate of change growth factors for the corresponding measure of self-esteem; where applicable, both types of pathways were considered together as constituting a single mediational chain linking the relevant social support growth factor to a given growth factor for a measure of adjustment. The multiple possible mediational chains for each model (i.e., those linking each pairing of growth factors for measures of social support and adjustment) were evaluated in separate analyses. This was done to avoid problems of overfitting that might have resulted from adding multiple direct paths linking social support and adjustment growth factors to any given model. For each mediational chain found to be significant, we estimated its magnitude using both unstandardized and standardized estimates of effect. The latter, standardized estimates can be interpreted as the predicted degree of change in the relevant growth factor for adjustment, in standard deviation units, in response to a 1 standard deviation change in the growth factor for social support, limiting consideration to those changes that would be predicted to occur via intermediary linkages with growth factors for self-esteem.

As shown in Table 3, our findings reveal evidence of numerous mediational chains. These include chains in which general social support is linked to reduced levels and rates of growth in internalizing and externalizing problems via intermediary effects on gen- 
Table 3

Mediational Chains for Measures of Social Support, Self-Esteem, and Adjustment in Latent Growth Modeling Analyses

Mediational chain

Effect estimate $^{\mathrm{a}}$

Youth-report measures of social support/self-esteem and adjustment

Social support general (intercept Time 1) $\rightarrow$ Self-esteem general (intercept Time 3) $\rightarrow$ Internalizing problems (intercept Time 4)

Social support general (intercept Time 1) $\rightarrow$ Self-esteem general (intercept Time 3) $\rightarrow$ Externalizing problems (intercept Time 4)

Social support general (linear change) $\rightarrow$ Self-esteem general (linear change) $\rightarrow$ Internalizing problems (linear change)

Social support general (linear change) $\rightarrow$ Self-esteem general (intercept Time 3), Self-esteem general (linear change) $\rightarrow$ Externalizing problems (intercept Time 4)

Social support general (linear change) $\rightarrow$ Self-esteem general (linear change) $\rightarrow$ Externalizing problems (linear change)

Social support peer vs. adult sources ${ }^{\mathrm{b}}$ (intercept Time 1$) \rightarrow$ Self-esteem peer vs. adult sources $^{\mathrm{c}}$ (intercept Time 3 ) $\rightarrow$ Externalizing problems (intercept Time 4)

Social support peer vs. adult sources ${ }^{\mathrm{b}}$ (linear change) $\rightarrow$ Self-esteem peer vs. adult sources $^{\mathrm{c}}$ (linear change) ${ }^{\mathrm{b}} \rightarrow$ Externalizing problems (linear change)

Parent-report measures of social support/self-esteem and adjustment

Social support general (intercept Time 1) $\rightarrow$ Self-esteem general (intercept Time 3) $\rightarrow$ Internalizing problems (intercept Time 4)

Social support general (intercept Time 1) $\rightarrow$ Self-esteem general (intercept Time 3) $\rightarrow$ Externalizing problems (intercept Time 4)

Social support general (linear change) $\rightarrow$ Self-esteem general (linear change) ${ }^{\mathrm{d}} \rightarrow$ Internalizing problems (intercept Time 4)

Social support general (linear change) $\rightarrow$ Self-esteem general (linear change) $\rightarrow$ Externalizing problems (linear change)

Social support peer vs. adult sources ${ }^{\mathrm{b}}$ (intercept Time 1$) \rightarrow$ Self-esteem peer vs. adult sources $^{\mathrm{c}}$ (intercept Time 3 ) $\rightarrow$ Internalizing problems (intercept Time 4)

Social support peer vs. adult sources ${ }^{\mathrm{b}}$ (intercept Time 1$) \rightarrow$ Self-esteem peer vs. adult sources $^{\mathrm{c}}$ (intercept Time 3 ) $\rightarrow$ Externalizing problems (intercept Time 4)

Youth-report measures of social support/self-esteem and parent-report measures of adjustment

Social support general (intercept Time 1) $\rightarrow$ Self-esteem general (intercept Time 3) $\rightarrow$ Internalizing problems (intercept Time 4)

Social support general (intercept Time 1) $\rightarrow$ Self-esteem general (intercept Time 3) $\rightarrow$ Externalizing problems (intercept Time 4)

Social support peer vs. adult sources ${ }^{\mathrm{b}}$ (intercept Time 1 ) $\rightarrow$ Self-esteem peer vs. adult sources $^{\mathrm{c}}$ (intercept Time 3 ) $\rightarrow$ Externalizing problems (intercept Time 4)

Social support peer vs. adult sources ${ }^{\mathrm{b}}$ (linear change) $\rightarrow$ Self-esteem peer vs. adult sources $^{\mathrm{c}}$ (linear change) $\rightarrow$ Externalizing problems (linear change)

Parent-report measures of social support/self-esteem and youth-report measures of adjustment

Social support general (intercept Time 1) $\rightarrow$ Self-esteem general (intercept Time 3) $\rightarrow$ Internalizing problems (intercept Time 4)

$$
\begin{aligned}
& -0.85^{* * *}(-.33) \\
& -0.60^{* * *}(-.35) \\
& -1.28 *(-.37) \\
& -6.79 *(-.48) \\
& -0.68 *(-.34) \\
& 1.08 * * *(.13) \\
& 1.62 *(.32) \\
& -2.27 * * *(-.45) \\
& -2.39 * * *(-.33) \\
& -8.80^{* * *}(-.35)^{\mathrm{e}} \\
& -5.52 * * *(-.46)^{\mathrm{e}} \\
& -0.58^{* *}(-.08) \\
& 2.11^{* * *}(.21) \\
& -0.42 * * *(-.16) \\
& -0.48^{* *}(-.13) \\
& 1.65 * * *(.16)
\end{aligned}
$$

Note. $\quad N=350$. All mediational chains were tested in models that included a path representing the direct effect of the originating, predictor variable on the criterion measure. Only mediational effects that reached significance $(p<.05)$ are reported.

${ }^{a}$ All effects represent total indirect effects through all possible mediating variables in the model. Unstandardized effect estimates are reported, along with standardized effect estimates in parentheses.

${ }^{\mathrm{b}}$ Higher scores on this measure reflect ratings for peer social support that are relatively strong (i.e., favorable) in comparison with those for adult-oriented sources and vice versa for lower scores.

${ }^{\mathrm{c}}$ Higher scores on this measure reflect ratings for peer-oriented sources of self-esteem that are relatively strong (i.e., favorable) in comparison with those for adult-oriented sources and vice versa for lower scores.

${ }^{\mathrm{d}}$ This mediational chain also includes the intercept growth factor for the self-esteem measure; however, the path relating the social support growth factor to this growth factor was nonsignificant when testing the relevant structural model in primary analyses.

${ }^{\mathrm{e}}$ The analysis testing this mediational chain yielded a technically improper solution insofar as some standardized coefficient estimates exceeded their maximum permissible value (i.e., $>1$ ). This problem was rectified by setting the path representing the direct effect of the social support growth factor on the adjustment growth factor to a value of 0 ; the estimates reported are those obtained in this analysis, although the mediational chain involved reached or approached (i.e., $p<.10$ ) significance as well in the technically improper solution that allowed the relevant path to be freely estimated.

$* p<.05 . \quad * * p<.01 . \quad * * * p<.001$

eral self-esteem. Mediational chains of this form are statistically significant within each type of within-informant analysis and in each type of cross-informant analysis (although only a mediational chain involving internalizing problems is significant when using parent-report measures of social support/self-esteem and youthreport measures of adjustment). Several mediational chains involving relative degree of balance in peer versus adult sources of social support and self-esteem also are significant. With only one excep- tion, these take the form of imbalance in the direction of a peer-oriented pattern in social support being linked to greater levels or rate of growth in externalizing problems via its intermediary contribution to a similar peer-oriented pattern in self-esteem. This type of mediational chain is evident within both types of within-informant analyses and in the cross-informant analysis based on youth-report measures of social support/self-esteem and parent-report measures of adjustment (see Table 3). The remaining 
mediational chain involving measures of peer versus adult balance pertains to prediction of internalizing problems in the withininformant analysis based on parent-report data.

In conducting the preceding analyses testing for mediation, we seldom found paths representing direct effects of social support on adjustment to be significant. ${ }^{5}$ The two primary exceptions pertain to the model based on within-informant analysis of parent-report data. These include a significant direct path from the Time 1 general social support intercept factor to the Time 4 externalizing problems intercept factor $(b=-1.29, p<.01)$ despite the significant mediational chain linking these two factors as well as a significant direct path from rate of change in general social support to rate of change in internalizing problems $(b=-0.91, p<.01)$ in the context of a nonsignificant mediational chain linking these two factors. Overall, results thus are consistent with strong or complete mediation (Holmbeck, 1997; Kenny et al., 1998) in which linkages between growth factors for social support and adjustment can be accounted for predominantly by intervening linkages with growth factors for self-esteem.

In the preceding analyses, we derived growth factors for social support and self-esteem within any given analysis using data from the same informant. Supplementary analyses thus examined whether mediational chains involving social support, self-esteem, and adjustment remained evident when instead using a crossinformant approach for this portion of the model-that is, youthreport measures of social support and parent-report measures of self-esteem or, alternatively, parent-report measures of social support and youth-report measures of self-esteem. Results of both types of analyses continued to include significant linkages between growth factors for social support and self-esteem in a manner consistent with findings reported previously (see Figures 2 and 3). Mediational chains linking growth factors for general social support and peer versus adult sources of support to growth factors for adjustment problems via intermediary linkages with growth factors for corresponding aspects of self-esteem, furthermore, remained evident in each type of analysis and follow the same pattern as those found in primary analyses. ${ }^{6}$

Moderating effects of age. To investigate possible moderating effects of age, we evaluated the structural models relating growth factors for social support, self-esteem, and adjustment for differences across relatively younger and older youth within the sample. Younger and older cohorts were identified on the basis of a median split of the sample according to age (young cohort: $M=10.68$ years, $S D=0.46$; older cohort: $M=12.7$ years, $S D=0.81)$. Multisample analyses (Bollen, 1989) then were conducted with the EQS software to test for differences across cohorts in the magnitude and/or direction of paths linking constructs in the hypothesized model. This was accomplished by testing for differences in the chi-square index of overall model fit when constraining either any of the individual model paths or the full set of 18 possible paths to be equal across age cohorts (Bollen, 1989). All other model parameters were free to vary across cohorts in these analyses; however, paths representing effects of age on growth factors were not included given that youth were being grouped according to this variable. Using the preceding approach, we found neither individual paths nor all paths considered together to vary significantly across age cohorts in any of the within- or cross-informant analyses.

\section{Discussion}

Results of this research are consistent with the view that social support and self-esteem are resources promoting favorable adjustment in early adolescence. Specifically, higher levels and rates of growth for each type of resource were found to be associated with reduced levels and rates of growth in emotional and behavioral problems over a 2-year period. These linkages are evident in both within- and cross-informant analyses based on several differing combinations of youth- and parent-report data. Similar findings have been reported in other longitudinal research (Cheng, 1997; DuBois, Felner, Meares, \& Krier, 1994; Jessor, Turbin, \& Costa, 1998; Owens, 1994; Rosenberg, Schooler, \& Schoenbach, 1989; Short et al., 1996; Zimmerman, Ramirez-Valles, Zapert, \& Maton, 2000). Prior studies, however, have not used data analytic strategies capable of incorporating parameters of individual growth in constructs over time. They also have not used a fully elaborated multi-informant assessment strategy as an additional source of methodological control. Substantively, our results build on previous research in two significant areas. One is the processes through which social support and self-esteem may combine together to influence trajectories of adjustment among young adolescents. The other is the role of patterning or balance in sources of each type of resource in shaping adaptive outcomes during early adolescence.

\section{Self-Esteem as a Mediator of Effects of Social Support on Adjustment}

With respect to the first concern, our results are consistent with self-esteem having a significant role in mediating positive contributions of social support to the emotional and behavioral adjustment of young adolescents. The use of longitudinal data in tests for mediation serves to strengthen the basis for concluding that selfesteem is involved in processes accounting for effects of social support on adjustment during early adolescence (DuBois, Felner, Sherman, \& Bull, 1994; Harter, 1985, 1999; Shagle \& Barber, 1995). The use of multi-informant data, aside from adding further methodological rigor to tests for mediation, is also noteworthy from a substantive, theoretical perspective. This is because ratings of social support and self-esteem obtained from youth and parents may have tapped somewhat differing but mutually important dimensions of each construct. With regard to social support, ratings obtained from youth assessed their subjective experiences of the support they received from others. In comparison, parent ratings were geared toward their impressions of the objective levels of support that youth received. Both types of information tap significant components of social support during adolescence (Cauce et al.,1996; Gottlieb, 1991). Similarly, youth ratings of self-esteem necessarily focused on their own internalized self-evaluations.

\footnotetext{
${ }^{5}$ In addition to nonsignificant direct paths from social support to adjustment factors, we found a few paths that were significant but in directions opposite to those expected (e.g., path with positive coefficient from general social support to adjustment problems). These paths are most likely a methodological artifact of having already taken into account the majority of theoretically expected associations between social support and adjustment through mediational pathways of influence involving self-esteem (Kenny et al., 1998).

${ }^{6}$ Complete results of these analyses are available from David L. DuBois upon request.
} 
Parent ratings, however, may have been influenced to a greater extent by outward manifestations of self-esteem exhibited by youth (i.e., presented self-esteem; see Demo, 1985; Harter, 1999). On the basis of these considerations and the consistency of findings across analyses using youth and parent ratings, it thus would appear that mediational processes involving support and esteem may have broad relevance to differing facets of each type of resource.

In tests for mediation, paths representing direct effects of social support on adjustment were generally found to be nonsignificant. This suggests that mediational linkages involving self-esteem are relatively strong and thus more consistent with complete, rather than partial, mediation (Holmbeck, 1997). Developmental considerations suggest that during the transition to adolescence, adaptive benefits of social support may increasingly become tied to whether they promote growth in internalized resources (e.g., self-esteem). Esteem-enhancing interactions with significant others accordingly may assume an influential role in processes of adjustment throughout early adolescence (Short et al., 1996). It is therefore noteworthy that in the present sample, there are some indications of reduced levels of social support and self-esteem for older youth. These include negative relations between age and overall levels of social support and self-esteem as reported by youth. Developmental trends of this type were not entirely consistent. Decreases in social support and self-esteem during early adolescence have been reported in other research, however, and have been linked to disruptive effects of puberty, school transitions, and other aspects of change that characterize this stage of development (Lerner et al., 1996; Simmons \& Blyth, 1987). Even if only temporary, such trends have the potential to inhibit processes through which the two resources can contribute to adjustment.

These developmental considerations notwithstanding, we found no evidence of a possible shift toward increasingly strong mediational effects of self-esteem for older youth who had progressed more fully into adolescence. One factor that could have contributed to this finding is the range of ages included in the sample. It may be that a salient mediational role for self-esteem first emerges earlier during preadolescence, for example, or does not realize its full potential until later stages of adolescence. Any shift that does occur also may be linked more closely to specific areas of developmental change (e.g., increased capacities for self-reflection) than to chronological age. Finally, from a methodological standpoint, analyses considered differences across only relatively younger and older cohorts in the sample, as opposed to more refined gradations of age. This was necessitated by constraints related to sample size and the relative complexity of the models being evaluated. These circumstances, however, may have limited ability to detect more subtle age-related changes in relations under study.

\section{Peer Versus Adult Sources of Social Support and Self-Esteem}

Further results highlight the importance of considering not only overall levels of social support and self-esteem but also relative balance in peer versus adult sources of each type of resource in early adolescence. Most notably, a pattern of relatively strong ratings for peer-oriented domains compared with adult-oriented domains (i.e., school and family) was revealed to be linked consistently to increased levels and rate of growth in externalizing problems during this developmental period. Previous studies have indicated a similar trend toward behavioral problems for young adolescents with relatively pronounced peer-oriented bases for social support (Dubow, Edwards, \& Ippolito, 1997; Seidman et al., 1999) and feelings of self-worth (DuBois, Bull, et al., 1998; DuBois et al., 1999). Findings of the current investigation represent a significant extension of this work. Methodologically, they provide evidence of liability associated with peer-oriented patterns of support and esteem longitudinally and based on perspectives of both youth and adult informants. From a theoretical perspective, a noteworthy aspect of the results is the manner in which we found greater support from peers, relative to family members and school personnel, to be linked indirectly to behavioral problems via its association with a corresponding tendency toward peer-oriented bases for feelings of self-worth. This finding suggests that mediational pathways involving differing configurations in sources of support and esteem may operate in tandem with those involving absolute levels of each resource. Such processes would be consistent with the well-documented importance of multiple, complex pathways linking psychosocial factors to adjustment outcomes during adolescence (Compas et al., 1995; Steinberg \& Morris, 2000).

Further mechanisms specific to peer-oriented developmental imbalance in sources of self-esteem and social support may be important for understanding its observed linkage with growth in externalizing problems. When adult-oriented domains (i.e., family and school) are relatively weak sources of support and esteem, this may detract from the capacities of youth to cope successfully with stressors (e.g., parent-child conflict) and other adaptive demands (e.g., increased academic expectations) encountered in these contexts during transition to adolescence. Peer-oriented domains, at the same time, may be regarded by young adolescents as increasingly viable sources of social support and self-esteem (Kaplan, 1996). Accordingly, when faced with negative experiences in adult-oriented settings, they may be disposed to seek out support and feelings of worth predominantly in peer-oriented pursuits, despite the potential for doing so to involve maladaptive tendencies such as avoidance of responsibilities at school or home and cultivation of associations with problem peers (DuBois, Bull, et al., 1998). Self-esteem in particular has well-established implications for the motivational orientations of youth that are consistent with this possibility (Harter, 1999; Rosenberg, 1979). These include tendencies to value and engage in efforts to strengthen existing, positive sources of feelings of worth (e.g., peer friendships) while relatively devaluing and devoting less effort to areas (e.g., schoolwork) not experienced as esteem enhancing. Disproportionately favorable self-evaluations for peer-oriented, as opposed to adult-oriented, domains thus may contribute directly to attitudes and patterns of activity that increase risk for involvement in problem behavior during early adolescence.

In accordance with these considerations, there are several indications in the present findings of increasingly peer-oriented patterns of social support and self-esteem during the transition into adolescence. Older youth in the sample, for example, reported significantly more pronounced tendencies toward peer-oriented sources of both support and esteem than did younger youth. These trends suggest that peer-oriented patterns of support and esteem may become a more common factor contributing to behavioral problems as youth progress fully into adolescence. Yet evidence of a corresponding pattern of increase in behavioral difficulties with age, as might then be expected, is lacking. One possible explana- 
tion is that strong patterns of peer emphasis can be viewed as increasingly normative during the transition to adolescence (Lerner et al., 1996). For this reason, tendencies for peers and related domains to be salient sources of support and esteem may have presented less risk for negative adjustment outcomes among older youth in the sample. The lack of a moderating effect for age on paths from peer versus adult balance to externalizing problems is not entirely consistent with this interpretation. As noted previously, however, methodological issues may have limited the sensitivity of analyses in this area.

Relative balance of peer versus adult sources for social support and self-esteem was not linked in a consistent direction to growth factors for internalizing problems. When considering youths' own reports of support and esteem, relatively strong ratings for peeroriented domains were predictive of increased emotional difficulties. By contrast, for analyses using parent reports of each resource, findings were in the opposite direction such that imbalance favoring school and family domains was predictive of greater internalizing problems. Methodological factors are thus one possible explanation. It also could be that differing subgroups of youth are prone to exhibit emotional problems in response to patterns of relative imbalance in each direction. Consistent with this possibility, Harter (1999) reported finding one cluster of depressed youth with a profile of self-perceptions more favorable for parent-salient domains than peer-oriented domains, whereas another cluster had a mirror-image profile in which self-perceptions were very favorable for peer-salient domains but negative for parent-salient domains. Individual difference factors that might account for such variation include the relative value or importance that youth attach to peer- and adult-oriented domains of experience, respectively, as bases for feelings of self-worth (Harter, 1999).

\section{Applied Implications}

From an applied perspective, findings suggest the benefits of including activities directed toward enhancement of both social support and self-esteem in interventions for young adolescents. Promotion of the two types of resources in tandem is a recommended strategy for the design of successful programs in the prevention literature (Gullotta, 1997). On the basis of the current results, one useful goal would be to orient programs toward facilitating mediational processes through which the two types of resources can contribute together to positive adjustment outcomes. This might entail provisions to increase availability of social support as a key component of esteem-enhancement interventions for young adolescents (Harter, 1999). Attention is also warranted to ensure that differing sources of support and esteem for this age group are fostered in ways that allow for a healthy balance across peer- and adult-oriented domains of activity. Findings indicating problematic trends in levels and patterning of each type of resource during early adolescence underscore the potential significance of these concerns and clearly are consistent with the recommendation that this developmental stage be targeted in preventive interventions (Lerner et al., 1996).

\section{Limitations and Future Directions}

Several limitations and directions for future research also should be noted. Despite the relative rigor of the longitudinal and multiinformant design, our results do not necessarily indicate causal influences. One issue in this regard is that estimated rate of change parameters, derived through LGM, were based on the same waves of assessment for all constructs. As a result, these growth parameters, when examined in structural modeling analyses, were not temporally distinct from one another in a manner ideally suited for discerning directional relations among social support, self-esteem, and adjustment over time. In future research, greater temporal resolution might be pursued through the use of additional times of assessment. This would make it possible to derive estimates of rates of growth for support, esteem, and adjustment that are based on differing (i.e., nonoverlapping) waves of measurement. A related issue is that other factors not considered in the present research may be important sources of shared influence on social support, self-esteem, and adjustment in early adolescence. The absence of control for such factors could account at least in part for the observed relations among measures of support, esteem, and adjustment problems. Future investigations should address this concern by incorporating a broader array of potential explanatory factors with respect to adolescent functioning.

A further limitation is that our findings do not address the full range of aspects of early adolescent adjustment that may be influenced by social support and self-esteem. One useful direction to pursue in future investigations would be to include criterion measures assessing positive mental health as opposed to only problems or negative adjustment in future investigations (Compas, 1993). Relatedly, because of the relatively short time frame of the study, it also was not possible to explore long-term implications that the aspects of support and esteem examined may have for adjustment at subsequent stages of development.

Finally, the current research should be viewed as only a first step in efforts to delineate processes linking social support, self-esteem, and adjustment during the transition to adolescence. Future work should consider other types of processes that may link these constructs in early adolescence, including interactions between support and esteem as influences on adjustment (see, e.g., Dubow et al., 1997) as well as reciprocal effects of adjustment outcomes on levels of each resource (see, e.g., Cheng, 1997; Owens, 1994). Greater depth of understanding regarding processes should be pursued as well. This might be facilitated by a variety of approaches, such as a microanalytic, diary-based approach in which relevant variables are assessed repeatedly over short intervals of time (e.g., daily). Recent applications of this methodology with adult samples have proven informative (Lazarus, 2000) and offer a useful starting point for exploring its utility at earlier stages of development.

\section{References}

Achenbach, T. M. (1991a). Manual for the Child Behavior Checklist and 1991 Profile. Burlington: University of Vermont Department of Psychiatry.

Achenbach, T. M. (1991b). Manual for the Youth Self-Report and 1991 Profile. Burlington: University of Vermont Department of Psychiatry.

Bentler, P. M. (1996). EQS: A structural equations program (Version 5. 1) [Computer software]. Encino, CA: Multivariate Software.

Berndt, T., \& Hestenes, S. L. (1996). The developmental course of social support: Family and peers. In L. Smolak, M. P. Levine, \& R. StriegelMoore (Eds.), The developmental psychopathology of eating disorders: Implications for research, prevention, and treatment (pp. 77-106). Mahwah, NJ: Erlbaum.

Bollen, K. A. (1989). Structural equations with latent variables. New York: Wiley. 
Brinthaupt, T. M., \& Erwin, L. J. (1992). Reporting about the self: Issues and implications. In T. M. Brinthaupt \& R. P. Lipka (Eds.), The self: Definitional and methodological issues (pp. 137-171). Albany: State University of New York Press.

Bronfenbrenner, U. (1979). The ecology of human development: Experiments by nature and design. Cambridge, MA: Harvard University Press.

Cauce, A. M., Mason, C., Gonzales, N., Hiraga, Y., \& Liu, G. (1996). Social support during adolescence: Methodological and theoretical considerations. In K. Hurrelmann \& S. F. Hamilton (Eds.), Social problems and social contexts in adolescence: Perspectives across boundaries (pp. 131-151). New York: Aldine de Gruyter.

Cheng, C. (1997). Role of perceived social support on depression in Chinese adolescents: A prospective study examining the buffering model. Journal of Applied Social Psychology, 27, 800-820.

Compas, B. E. (1993). Promoting positive mental health during adolescence. In S. G. Millstein, A. C. Petersen, \& E. O. Nightingale (Eds.), Promoting the health of adolescents: New directions for the twenty-first century (pp. 159-179). New York: Oxford University Press.

Compas, B. E., Hinden, B. R., \& Gerhardt, C. A. (1995). Adolescent development: Pathways and processes of risk and resilience. Annual Review of Psychology, 46, 265-293.

Connell, J. P., Spencer, M. B., \& Aber, J. L. (1994). Educational risk and resilience in African-American youth: Context, self, action, and outcomes in school. Child Development, 65, 493-506.

Demo, D. H. (1985). The measurement of self-esteem: Refining our methods. Journal of Personality and Social Psychology, 48, 1490-1502.

Douvan, E., \& Adelson, J. (1966). The adolescent experience. New York: Wiley.

DuBois, D. L. (1993). Child Self-Esteem Questionnaire. Unpublished questionnaire, University of Missouri-Columbia.

DuBois, D. L., Brooks, M. M., Davis, K. M., Gok, N., \& Odum, J. (1998, August). Ecological correlates of self-esteem among young adolescents. Paper presented at the 106th Annual Convention of the American Psychological Association, San Francisco, CA.

DuBois, D. L., Bull, C. A., Sherman, M. D., \& Roberts, M. (1998). Self-esteem and adjustment in early adolescence: A social-contextual perspective. Journal of Youth and Adolescence, 27, 557-583.

DuBois, D. L., Felner, R. D., Brand, S., \& George, G. R. (1999). Profiles of self-esteem in early adolescence: Identification and investigation of adaptive correlates. American Journal of Community Psychology, 27, 899-932.

DuBois, D. L., Felner, R. D., Brand, S., Phillips, R. S. C., \& Lease, A. M. (1996). Early adolescent self-esteem: A developmental-ecological framework and assessment strategy. Journal of Research on Adolescence, 6, 543-579.

DuBois, D. L., Felner, R. D., Meares, H., \& Krier, M. (1994). Prospective investigation of the effects of socioeconomic disadvantage, life stress, and social support on early adolescent adjustment. Journal of Abnormal Psychology, 103, 511-522.

DuBois, D. L., Felner, R. D., Sherman, M. D., \& Bull, C. A. (1994). Socio-environmental experiences, self-esteem, and emotional/behavioral problems in early adolescence. American Journal of Community Psychology, 22, 371-397.

DuBois, D. L., \& Tevendale, H. D. (1999). Self-esteem in childhood and adolescence: Vaccine or epiphenomenon? Applied and Preventive Psychology, 8, 103-117.

Dubow, E. F., Edwards, S., \& Ippolito, M. F. (1997). Life stressors, neighborhood disadvantage, and resources: A focus on inner-city children's adjustment. Journal of Clinical Child Psychology, 26, 130-144.

Edens, J. F, Cavell, T. A., \& Hughes, J. N. (1999). The self-systems of aggressive children: A cluster-analytic investigation. Journal of Child Psychology \& Psychiatry and Allied Disciplines, 40, 441-453.

Gottlieb, B. H. (1991). Social support in adolescence. In M. E. Colten \& S. Gore (Eds.), Adolescent stress: Causes and consequences (pp. 281-306). New York: Aldine de Gruyter.
Gregorich, S. (2001). EM_COVAR. SAS: A SAS/IML Macro for Estimating a Covariance Matrix and Mean Vector Via the Expectation Maximization (EM) Algorithm [Computer program]. San Francisco: Center for AIDS Prevention Studies, University of California at San Francisco.

Gullotta, T. P. (1997). Operationalizing Albee's incidence formula. In G. W. Albee \& T. P. Gullotta (Eds.), Primary prevention works (pp. 23-37). Thousand Oaks, CA: Sage.

Hamburg, B. (1974). Early adolescence: A specific and stressful stage of the life cycle. In G. Coelho, D. Hamburg, \& J. Adams (Eds.), Coping and adaptation (pp. 101-124). New York: Basic Books.

Harter, S. (1985). Processes underlying the construction, maintenance and enhancement of the self-concept in children. In J. Suls \& A. Greenwald (Eds.), Psychological perspectives on the self (Vol. 3, pp. 137-181). Hillsdale, NJ: Erlbaum.

Harter, S. (1999). The construction of the self: A developmental perspective. New York: Guilford Press.

Holmbeck, G. N. (1997). Toward terminological, conceptual, and statistical clarity in the study of mediators and moderators: Examples from the child-clinical and pediatric psychology literatures. Journal of Consulting and Clinical Psychology, 65, 599-610.

Jessor, R., Turbin, M. S, \& Costa, F. M. (1998). Protective factors in adolescent health behavior. Journal of Personality and Social Psychology, 75, 788-800.

Kaplan, H. B. (1996). Psychosocial stress from the perspective of selftheory. In H. B. Kaplan (Ed.), Psychosocial stress: Perspectives on structure, theory, life-course, and methods (pp. 175-244). San Diego, CA: Academic Press.

Kenny, D. A., Kashy, D. A., \& Bolger, N. (1998). Data analysis in social psychology. In D. T. Gilbert, S. T. Fiske, \& G. Lindzey (Eds.), The handbook of social psychology (Vol. 1, pp. 233-265). Boston: McGrawHill.

Larson, R. W. (1997). The emergence of solitude as a constructive domain of experience in early adolescence. Child Development, 68, 80-93.

Lazarus, R. S. (2000). Toward better research on stress and coping. American Psychologist, 55, 665-673.

Lerner, R. M., Lerner, J. V., von Eye, A., Ostrom, C. W., Nitz, K., Talwar-Suni, R., \& Tubman, J. G. (1996). Continuity and discontinuity across the transition of early adolescence: A developmental contextual perspective. In J. A. Graber, J. Brooks-Gunn, \& A. C. Petersen (Eds.), Transitions through adolescence: Interpersonal domains and context (pp. 3-22). Mahwah, NJ: Erlbaum.

Little, R. J. A., \& Rubin, D. B. (1987). Statistical analysis with missing data. New York: Wiley.

Magnusson, D. (1995). Individual development: A holistic, integrated model. In P. Moen, G. H. Elder, \& K. Luscher (Eds.), Examining lives in context: Perspectives on the ecology of human development ( $\mathrm{pp}$. 19-60). Washington, DC: American Psychological Association.

Marsh, H. W., \& Craven, R. G. (1991). Self-other agreement on multiple dimensions of preadolescent self-concept: Inferences by teachers, mothers, and fathers. Journal of Educational Psychology, 83, 393-404.

Muthen, B., Kaplan, D., \& Hollis, M. (1987). On structural equation modeling with data that are not missing completely at random. Psychometrika, 52, 431-462.

Newcomb, M. D., \& Keefe, K. (1997). Social support, self-esteem, social conformity, and gregariousness: Developmental patterns across 12 years. In G. Pierce \& B. Lakey (Eds.), Sourcebook of social support and personality (pp. 303-333). New York: Plenum.

Owens, T. J. (1994). Two dimensions of self-esteem: Reciprocal effects of positive self-worth and self-depreciation on adolescent problems. American Sociological Review, 59, 391-407.

Pedhazur, E. J. (1997). Multiple regression in behavioral research (3rd ed.). New York: Holt, Rinehart \& Winston.

Petersen, A. C., Kennedy, R. E., \& Sullivan, P. A. (1991). Coping with adolescence. In M. E. Colten \& S. Gore (Eds.), Adolescent stress: Causes and consequences (pp. 93-110). New York: Aldine de Gruyter. 
Procidano, M. E., \& Heller, K. (1983). Measures of perceived social support from friends and from family: Three validation studies. American Journal of Community Psychology, 11, 1-24.

Rosenberg, M. (1979). Conceiving the self. New York: Basic Books.

Rosenberg, M., Schooler, C., \& Schoenbach, C. (1989). Self-esteem and adolescent problems: Modeling reciprocal effects. American Sociological Review, 54, 1004-1018.

Sandler, I. N., Miller, P., Short, J., \& Wolchik, S. (1989). Social support as a protective factor for children in stress. In D. Belle (Ed.), Children's social networks and social supports (pp. 277-307). New York: Wiley.

Sandler, I. N., Tein, J., Mehta, P., Wolchik, S., \& Ayers, T. (2000). Coping efficacy and psychological problems of children of divorce. Child Development, 71, 1099-1118.

Sandler, I. N., \& Twohey, J. L. (1998). Conceptualization and measurement of coping in children and adolescents. Advances in Clinical Child Psychology, 20, 243-301.

Seidman, E., Chesir-Teran, D., Friedman, J. L, Yoshikawa, H., Allen, L., $\&$ Roberts, A. (1999). The risk and protective functions of perceived family and peer microsystems among urban adolescents in poverty. American Journal of Community Psychology, 27, 211-237.

Shagle, S. C., \& Barber, B. K. (1995). A social-ecological analysis of adolescent suicidal ideation. American Journal of Orthopsychiatry, 65, $114-124$

Short, J. L., Sandler, I. N., \& Roosa, M. W. (1996). Adolescents’ percep- tions of social support: The role of esteem enhancing and esteem threatening relationships. Journal of Social and Clinical Psychology, 15, 397-416.

Simmons, R. G., \& Blyth, D. A. (1987). Moving into adolescence: The impact of pubertal change and school context. New York: Aldine de Gruyter.

Steinberg, L., \& Morris, A. S. (2000). Adolescent development. Annual Review of Psychology, 52, 83-110.

Willett, J. B., \& Sayer, A. G. (1994). Using covariance structure analysis to detect correlates and predictors of individual change over time. Psychological Bulletin, 116, 363-381.

Willett, J. B., Singer, J. D., \& Martin, N. C. (1998). The design and analysis of longitudinal studies of development and psychopathology in context: Statistical models and methodological recommendations. Development and Psychopathology, 10, 395-426.

Zimmerman, M. A, Ramirez-Valles, J., Zapert, K. M., \& Maton, K. I. (2000). A longitudinal study of stress-buffering effects for urban African-American male adolescent problem behaviors and mental health. Journal of Community Psychology, 28, 17-33.

Received August 3, 2000

Revision received April 22, 2002

Accepted April 22, 2002 